\title{
Auditory and Visual P300 in ADHD Children with Higher and Lower IQ : Pilot Study
}

\author{
Sheng Min Wang, M.D., Yang-Whan Jeon, M.D., Ph.D., \\ Sang-Ick Han, M.D., Ph.D. and E Jin Park, M.D., Ph.D. \\ Department of Psychiatry, Incheon St. Mary's Hospital, The Catholic University of Korea, Incheon, Korea
}

\begin{abstract}
Objectives : Intellectual impairment in children with attention-deficit hyperactivity disorder (ADHD) is often associated with relatively severe cognitive dysfunction. This study was designed to investigate cognitive function using auditory and visual event-related potential P300 in children with ADHD with relatively higher and lower IQ.

Methods : A total of 20 children aged 6-12 years with DSM-IV-TR diagnosis of ADHD-combined type were recruited. For 10 children with lower IQ $(\leq 100)$ and 10 children with higher IQ $(>100)$, auditory and visual P300 using oddball paradigm (target 0.2 , standard 0.8 , in probability) were employed.

Results : No significant differences were found in P300 amplitude and latency between ADHD children with higher and lower IQ in both modalities. However, auditory P300 amplitude in the right parietal area (P8 electrode) was negatively correlated with verbal IQ in ADHD subjects $(\mathrm{R}=-.50, \mathrm{p}<.05)$. Visual $\mathrm{P} 300$ amplitude in the left parietal area (P3 electrode) was positively correlated with performance IQ in ADHD subjects $(\mathrm{R}=.57, \mathrm{p}<.01)$.

Conclusion : This study suggests intellectual impairment, as evidenced by lower IQ, could not be associated with cognitive dysfunction reflected in event-related potential P300 in ADHD children. However, cognitive function reflected in intellectual subcomponents and P300 might be processed in a stimulus modality-specific and asymmetric pattern.
\end{abstract}

KEY WORDS : Attention-Deficit Hyperactivity Disorder · Cognition · P300.

\section{Introduction}

Attention-deficit hyperactivity disorder (ADHD) is one of the most common psychiatric disorders in childhood with a prevalence rate of approximately $5 \%$ of children and adolescents. ${ }^{1)}$ Clinically, it is characterized by inattention, impulsivity, and hyperactivity. ${ }^{2)}$ ADHD is a disorder with various co morbidities, including but not limited to conduct disorder, oppositional defiant disorder, obsessive compulsive disorder, substance use disorder, and major depressive disorder. $^{3-6)}$

Similar to the general population, children with ADHD have a broad range of intellectual abilities. ${ }^{7)}$ Studies suggest that levels of intellectual function might play an important role in the prognosis of ADHD. For example, reports have suggested that ADHD could more likely be present in the

Received : May 30, 2011 / Accepted : July 27, 2011

Address for correspondence:E Jin Park, M.D., Ph.D., Department of Psychiatry, Incheon St. Mary's Hospital, The Catholic University of Korea, 56 Dongsu-ro, Bupyeong-gu, Incheon 403-720, Korea

Tel : +82.32-280-5980, Fax : +82.32-280-5556

E-mail : zahir@catholic.ac.kr context of developmental delay at the level of borderline to mild intellectual disability. ${ }^{8)}$ In addition, various studies have suggested that lower IQ might predict worse treatment response to both behavioral treatment and methylphenidate, whereas higher IQ might be a significant predictor of better treatment response. ${ }^{9)}$ Likewise, studies have also argued that lower IQ, in addition to poor parental management, presence of aggression, and low socioeconomic status, is recognized as an important factor predicting a poor outcome of ADHD. ${ }^{10,11)}$

Despite those facts, studies comparing ADHD children with lower intelligence and those with normal or higher intelligence are rare. Consequently, information regarding the developmental course and neuropathophysiological basis of ADHD in lower intelligence are even more limited.

Electrophysiological techniques, unlike many imaging studies, are not frequently used in studies investigating the pathophysiology of ADHD. However, electrophysiological techniques have many advantages over imaging studies in exploring perceptual and cognitive-processing deficits due to their functional relevance and high time resolution. ${ }^{12)}$ P300 (P3), among many, is one of the most well-known late 
event-related potential (ERP) components, and it has been widely studied in numerous psychiatric illnesses. Studies showed that it could reflect executive and attention functions, which are important cognitive domains of ADHD. ${ }^{13,14)}$

General consensus implies that the classic P3 amplitude resembles levels of cognitive resources devoted to stimulus processing, ${ }^{15)}$ and P3 latency reflects the processing speed to a given stimulus. ${ }^{14)}$ Moreover, it is generally believed that in children with ADHD, P3 amplitude is decreased, while the latency is increased. ${ }^{16)}$ The relationship between intelligence and P3 is less clear-cut. However, clinical studies have suggested that P3 amplitude is decreased and latency is increased in individuals with lower intelligence, results similar to those found in ADHD children. ${ }^{17)}$

The evidence suggests that $\mathrm{P} 3$ can be a promising means of investigating not only the underlying neuropathophysiological mechanisms of ADHD itself, but also the differences between ADHD children with lower IQ and those with higher IQ. Thus, the purpose of this study was to investigate and compare cognitive function using auditory and visual ERP P3 in ADHD children with relatively lower and higher IQ.

\section{Methods}

\section{Participants}

A retrospective chart review was conducted of children aged 6-12 years with no psychostimulant medication history, who underwent ERP tests, met the Diagnostic and Statistical Manual of Mental Disorders Fourth Edition, Text Revision (DSM-IV-TR) diagnostic criteria of ADHD-combined type, and visited Incheon St. Mary's Hospital, The Catholic University of Korea, from Jan. 1st 2004 through Dec. 31st 2004. This study was approved by the Institutional Review Board at Incheon St. Mary's Hospital, The Catholic University of Korea. A total of twenty children were included, and the participants were divided into two groups according to their IQs. Ten ADHD children with IQs ranging from 80 to 100 were grouped into the "lower IQ" group, and the other ten ADHD children with IQs higher than 100 but less than 125 were grouped into the "higher IQ" group. The evaluation of participants' IQs and recordings of ERPs were performed within a one week interval, shortly after their first visit to the clinic. The participants' IQ levels were tested via the Korean version of the Wechsler Intelligence Scale for Children III (K-WISC-III) by a trained clinical psychologist. WISC-III is composed of verbal and performance IQ tests. Verbal IQ tests an individual's level of information, digit span, vocabulary, arithmetic, comprehension, and similarities. Perfor- mance IQ contains picture completion, block design, matrix reasoning, digit symbol coding, and symbol search.

\section{Procedure and ERP recordings}

A total of twenty five electrodes were used to record electroencephalogram (EEG) for the ERP task. The sites of electrode placements were Fz, F3/4, F7/8 (frontal row), FCz, FC3/4, FC7/8 (fronto-central row), Cz, C3/4, T7/8 (central row), $\mathrm{CPz}, \mathrm{CP} 3 / 4$ (centro-parietal row), Pz, P3/4, P7/8 (parietal row), and M1/2 (mastoid), referred to the nose, with forehead ground and electrode impedance maintained below $5 \mathrm{k} \Omega$. In addition, electro ocular (EOG) activity was recorded using four other electrodes placed above and below both lateral canthi of the left eye. The range of bandpass was 0.05$30 \mathrm{~Hz}$. The EEG was digitized at $500 \mathrm{~Hz}$ for $1,000 \mathrm{~ms}$, with a prestimulus baseline of $100 \mathrm{~ms}$. To detect and reject signals due to eye-blinks, waveforms were averaged off-line, and any trials with EEG or EOG value that exceeded $\pm 100 \mu \mathrm{V}$ were excluded. To remove any remaining artifacts, all trial data underwent EOG correction. Finally, the largest positive-going peak that occurred within $300-800 \mathrm{~ms}$ at each electrode was defined as the P3 component.

\section{Stimulus}

Auditory stimuli were defined as standard $(1,000 \mathrm{~Hz})$ or target $(2,000 \mathrm{~Hz})$, presented in random series with probabilities of 0.8 and 0.2 , respectively, once every 2 seconds. Each stimulus was presented at $75 \mathrm{~dB}$ SPL intensity, $50 \mathrm{~ms}$ duration, and $10 \mathrm{~ms}$ rise/fall time.

Visual stimuli were defined as standard (small circle, $5 \mathrm{~cm}$ diameter) or target (large circle, $10 \mathrm{~cm}$ diameter) and were also presented in random series with probabilities of 0.8 and 0.2 , respectively, once every 2 seconds. Each stimulus was a solid white shape on a black background, presented at a medium intensity level and $100 \mathrm{~ms}$ duration on a computer monitor $1.5 \mathrm{~m}$ away from the subject.

EEG activity was recorded during each task condition, with 200 stimulus presentations lasting approximately seven minutes. Participants were instructed to look at the monitor in a relaxed state, avoid extraneous movements, press the mouse button with their right index fingers as quickly and accurately as possible when a target stimulus was presented, and refrain from responding to other stimuli. Response time was recorded.

\section{Statistical analysis}

All data processing was performed off-line using NEUROSCAN software. Comparisons of demographical findings between the two IQ groups were evaluated on the basis 
of the Fisher's exact test for categorical variables and the Mann-Whitney U test for continuous variables. A three-factor $[2$ group conditions (higher IQ and lower IQ) $\times$ five coronal electrode locations $\times$ three anterior-to-posterior electrode locations] analysis of variance (ANOVA) was applied to the amplitude and latency data of target stimulus P3. GreenhouseGeisser corrections to the degree of freedom were used to adjust for violations of the sphericity assumption for repeated measure factors containing more than two levels. Full scale IQs, subscale scores, and P3 measures were assessed with correlational procedures to quantify the relationships between IQ scores and P3. Correlation coefficients between ERPs and IQs were calculated by the Pearson test. Data were analyzed using Statistica (version 6.0).

\section{Results}

Table 1 summarizes the major demographic and clinical data of the participants.

Between the two IQ groups, there was no significant difference in each participant's response time to auditory (lower IQ, 553.55 $\pm 117.70 \mathrm{~ms}$; higher IQ, 567.71 $\pm 94.84 \mathrm{~ms} ; \mathrm{p}=.60$ ) and visual (lower IQ, 536.12 $\pm 96.60 \mathrm{~ms}$; higher IQ, $505.02 \pm$ $66.40114 \mathrm{~ms} ; \mathrm{p}=.41)$ stimuli at sites Fz, Cz, and Pz. Table 2 summarizes and compares P3 amplitude and latency between ADHD patients with lower IQs and those with higher IQs according to their electrode locations. Table 3 summarizes results of the three-factor ANOVA. Fig. 1 illustrates

Table 1. Baseline demographic characteristics

\begin{tabular}{|c|c|c|c|}
\hline & \multicolumn{2}{|c|}{ Group } & \multirow{2}{*}{$\mathrm{p}$} \\
\hline & Lower IQ $(80 \leq \mathrm{IQ} \leq 100)$ & Higher IQ $(100<1 Q<125)$ & \\
\hline Sex, n (\%) & & & .47 \\
\hline Male & $8(80)$ & $10(100)$ & \\
\hline Female & $2(20)$ & $0(0)$ & \\
\hline IQ (FSIQ), mean (SD) & $90.8(9.46)$ & $113.5(8.03)$ & $<.001$ \\
\hline IQ (VIQ), mean (SD) & $94.7(5.98)$ & $113.2(11.39)$ & \\
\hline IQ (PIQ), mean (SD) & $88.9(14.08)$ & $111(14.95)$ & \\
\hline Age (years), mean (SD) & $9.2(2.04)$ & $8.22(1.20)$ & .71 \\
\hline
\end{tabular}

FSIQ : Full Scale IQ, SD : Standard deviation, VIQ : Verbal IQ, PIQ : Performance IQ

Table 2. P300 amplitude and latency between ADHD with Lower IQ and higher IQ according to electrode locations

\begin{tabular}{|c|c|c|c|}
\hline & \multicolumn{3}{|c|}{ Electrode location } \\
\hline & $\mathrm{Fz}$ & $\mathrm{Cz}$ & $\mathrm{Pz}$ \\
\hline \multicolumn{4}{|l|}{ Auditory P300 amplitude } \\
\hline Lower IQ (mean $\pm S D)$ & $13.35 \pm 8.02$ & $22.21 \pm 8.55$ & $26.92 \pm 11.51$ \\
\hline Higher IQ (mean \pm SD) & $9.66 \pm 3.57$ & $19.31 \pm 8.02$ & $26.07 \pm 10.79$ \\
\hline $\mathrm{F}$ & 1.77 & .61 & .03 \\
\hline$P$ & .19 & .44 & .87 \\
\hline \multicolumn{4}{|l|}{ Auditory P300 Latency } \\
\hline Lower IQ (mean $\pm S D)$ & $442.20 \pm 60.75$ & $432.80 \pm 56.40$ & $429.40 \pm 35.35$ \\
\hline Higher IQ (mean \pm SD) & $456.90 \pm 56.16$ & $450.30 \pm 56.42$ & $450.30 \pm 65.64$ \\
\hline $\mathrm{F}$ & .32 & .48 & .79 \\
\hline$P$ & .58 & .49 & .39 \\
\hline \multicolumn{4}{|l|}{ Visual P300 amplitude } \\
\hline Lower IQ (mean $\pm S D)$ & $11.71 \pm 5.53$ & $25.99 \pm 7.38$ & $31.70 \pm 9.42$ \\
\hline Higher IQ (mean \pm SD) & $13.79 \pm 4.90$ & $26.30 \pm 9.30$ & $29.98 \pm 7.93$ \\
\hline $\mathrm{F}$ & .79 & .01 & .19 \\
\hline$P$ & .39 & .94 & .66 \\
\hline \multicolumn{4}{|l|}{ Visual P300 Latency } \\
\hline Lower IQ (mean $\pm S D)$ & $485.60 \pm 42.35$ & $493.00 \pm 45.94$ & $493.80 \pm 46.80$ \\
\hline Higher IQ (mean \pm SD) & $504.00 \pm 51.91$ & $500.20 \pm 52.89$ & $489.20 \pm 49.16$ \\
\hline $\mathrm{F}$ & .75 & .11 & .05 \\
\hline$P$ & .39 & .75 & .83 \\
\hline
\end{tabular}

SD : Standard deviation 
Table 3. Summary of F-ratios from three-factor [two group conditions (higher IQ and Lower IQ) five coronal electrode locations $\times$ three anterior-to-posterior electrode locations] analyses of variance performed on the P300 amplitude and latency from the target stimuli for auditory "oddball" paradigm

\begin{tabular}{|c|c|c|c|c|c|c|c|}
\hline \multirow{2}{*}{ Effect } & \multirow{2}{*}{ df } & \multicolumn{3}{|c|}{ P300 amplitude } & \multicolumn{3}{|c|}{ P300 latency } \\
\hline & & $\mathrm{F}$ & $\varepsilon$ & $\mathrm{p}$ & $\mathrm{F}$ & $\varepsilon$ & $\mathrm{p}$ \\
\hline \multicolumn{8}{|l|}{ Auditory } \\
\hline G & $(1,18)$ & .02 & - & - & .03 & - & - \\
\hline$A / P$ & $(2,36)$ & 83.19 & .69 & $<.001$ & 4.48 & .63 & .02 \\
\hline C & $(4,72)$ & 12.33 & .76 & $<.001$ & .27 & .79 & .85 \\
\hline$G \times A / P$ & $(2,36)$ & .44 & .69 & .88 & .61 & .63 & .46 \\
\hline$G \times C$ & $(4,72)$ & .50 & .76 & .87 & 1.58 & .79 & .78 \\
\hline$C \times A / P$ & $(8,144)$ & 6.35 & .54 & $<.001$ & 1.22 & .62 & .24 \\
\hline $\mathrm{G} \times \mathrm{C} \times \mathrm{A} / \mathrm{P}$ & $(8,144)$ & 1.70 & .54 & .35 & 2.07 & .62 & .15 \\
\hline \multicolumn{8}{|l|}{ Visual } \\
\hline G & $(1,18)$ & .03 & - & - & .70 & - & - \\
\hline $\mathrm{A} / \mathrm{P}$ & $(2,36)$ & 42.65 & .67 & $<.001$ & 11.39 & .72 & $<.01$ \\
\hline C & $(4,72)$ & 40.14 & .63 & $<.001$ & .35 & .65 & .76 \\
\hline$G \times A / P$ & $(2,36)$ & .52 & .67 & .44 & 2.24 & .72 & .14 \\
\hline$G \times C$ & $(4,72)$ & 1.79 & .63 & .67 & .18 & .65 & .89 \\
\hline$C \times A / P$ & $(8,144)$ & 15.46 & .57 & $<.001$ & 1.14 & .61 & .35 \\
\hline $\mathrm{G} \times \mathrm{C} \times \mathrm{A} / \mathrm{P}$ & $(8,144)$ & .80 & .57 & .36 & .86 & .61 & .51 \\
\hline
\end{tabular}

G : Groups (higher IQ vs. lower IQ), A/P : Anterior-to-posterior electrodes, C : Coronal electrodes

the comparison of mean P3 amplitude and latency between ADHD children with lower IQs and those with higher IQs from auditory stimuli, and Fig. 2 illustrates comparison from visual stimuli. Between ADHD children with lower IQs and those with higher IQs, no significant differences were found in P3 amplitude and latency in both modalities. However, as Table 4 illustrates, the amplitude of auditory P3 in the right parietal area (P8 electrode) was negatively correlated with verbal IQ ( $\mathrm{r}=-.50, \mathrm{p}<.05)$, whereas the amplitude of visual P3 in the left parietal area (P3 electrode) was positively correlated with performance IQ $(r=.57, \mathrm{p}<.01)$.

\section{Discussion}

The present study investigated and compared cognitive functions of ADHD children with relatively lower and higher IQs using auditory and visual event-related potential P3. Although no differences were observed in P3 amplitude and latency between the two groups, detailed analyses revealed that auditory P3 amplitude in the right parietal area (P8 electrode) was negatively correlated with verbal IQ, and amplitude of visual P3 in the left parietal area (P3 electrode) was positively correlated with performance IQ in ADHD children.

That result contradicts preceding theories. Studies have suggested that the right parietal lobe specializes in visualspatial relationships, ${ }^{17,18)}$ and the left hemisphere is recognized as having prominent roles in calculation, language, and symbol understanding. ${ }^{19-21)}$ Thus, theoretically, correlations between the auditory P3 amplitude of the left parietal area (not the auditory P3 amplitude in the right parietal area) and verbal IQ and between the visual P3 amplitude of the right parietal area (not the visual P3 amplitude in the left parietal area) and performance IQ would have been more expected and plausible results. One possible reason for this contradicting result might be attributable to differences in utilization of the brain in ADHD individuals. It is generally known that ADHD individuals have frontal lobe dysfunction. $^{22)}$ In order to compensate for that dysfunction, ADHD children might have more complex functions in other brain areas, especially those with higher intelligence. For example, those with higher IQ might have utilized not only their right parietal lobes but also their left parietal lobes to enhance their visual-spatial functioning, resulting in better performance IQ. That might explain the positive correlation between performance IQ and visual P3 amplitude in that left parietal area. However, that compensation hypothesis cannot explain the negative correlation between verbal IQ and auditory P3 amplitude in the right parietal area. In line with our results, studies suggesting the importance of other brain areas in ADHD, especially parietal lobe dysfunctions, are increasing. An event-related fMRI study suggested that bilateral parietal hypoactivation might be an important phenotype of ADHD. ${ }^{23)}$ Another fMRI study revealed that ADHD children have hypoactivation in only the right parietal cor- 
Fig. 1. Mean P300 amplitude (left panel) and latency (right panel) from target for auditory stimuli condition from the frontal, fronto-central, central, centro-parietal, and parietal arrays as a function of the coronal electrode site (LL : left lateral, LM : left medial, $M$ : medial $\mathrm{RM}$ : right medial, RL : right lateral) in ADHD children with lower and higher IQ

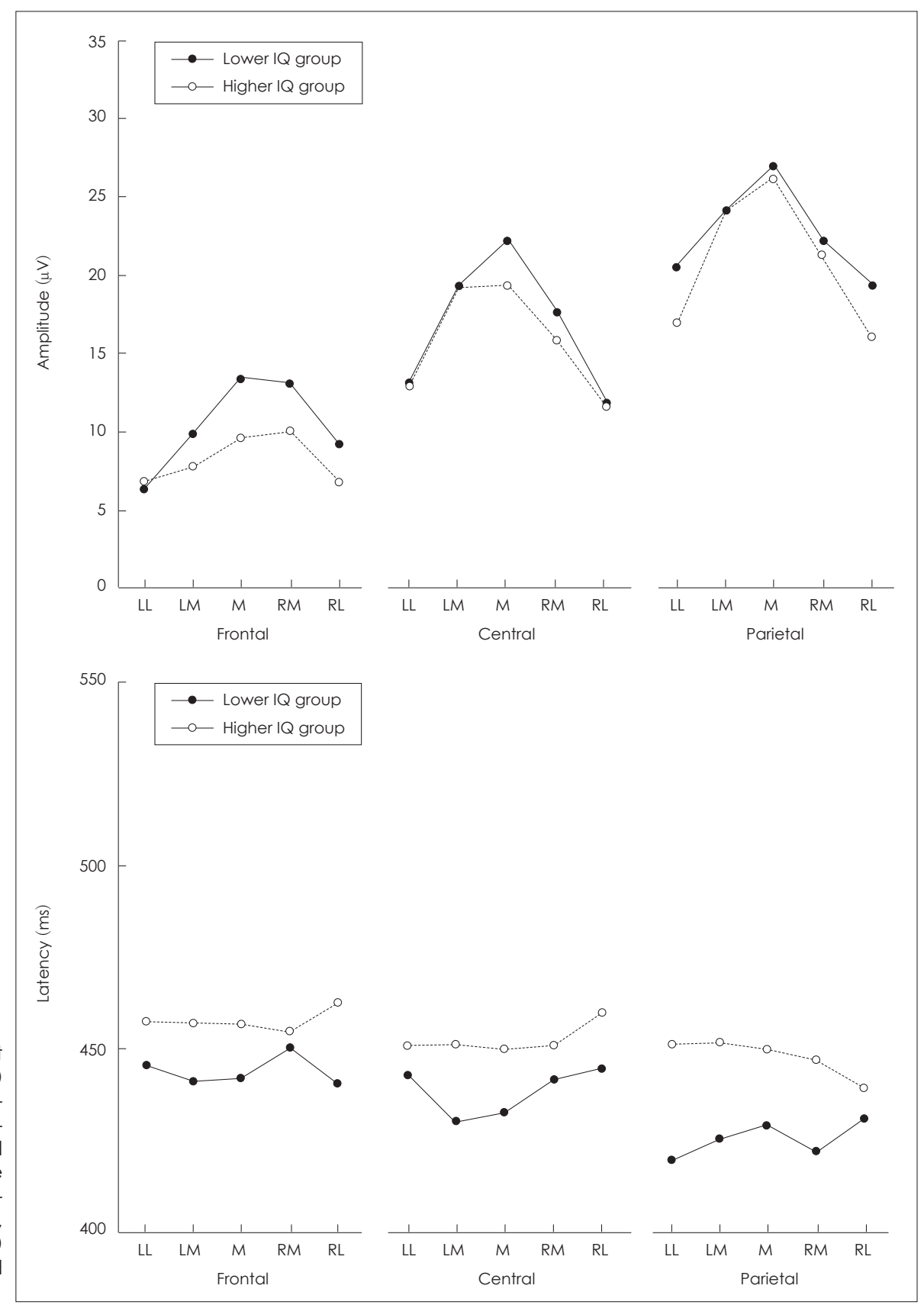

tex, ${ }^{24)}$ and others showed that those children have impaired right parietal activation during visual selective attention tasks. ${ }^{25)}$ In addition, studies using ERPs have further shown reduced amplitude to attentional orienting cues in the posterior parietal region. ${ }^{26,27)}$ Consistent with previous studies, the results of the present study suggest that the parietal lobe might have an important role in the neuropathophysiology of ADHD.

Some limitations of the study must be mentioned. First of all, P3 amplitude and latency in both modalities were not significantly different between ADHD children with lower IQs and those with higher IQs, which contradicted our hypothesis. The small sample size, which is our second limitation, might have been an important attributing factor. Furthermore, unlike many other studies illustrating correlation of lower IQ, with lower P3 amplitudes and delayed P3 latencies, which included either mental retardation $(\mathrm{IQ}<70)$ or a very superior IQ group (IQ>130), ${ }^{17,28,29)}$ the IQ range of the present study was narrower $(80 \leq \mathrm{IQ}<125)$. That might have lowered the mean difference of P3 amplitude and latency between the two IQ groups. Thirdly, it lacks comparison or a control group. Thus, it is difficult to analyze and compare 


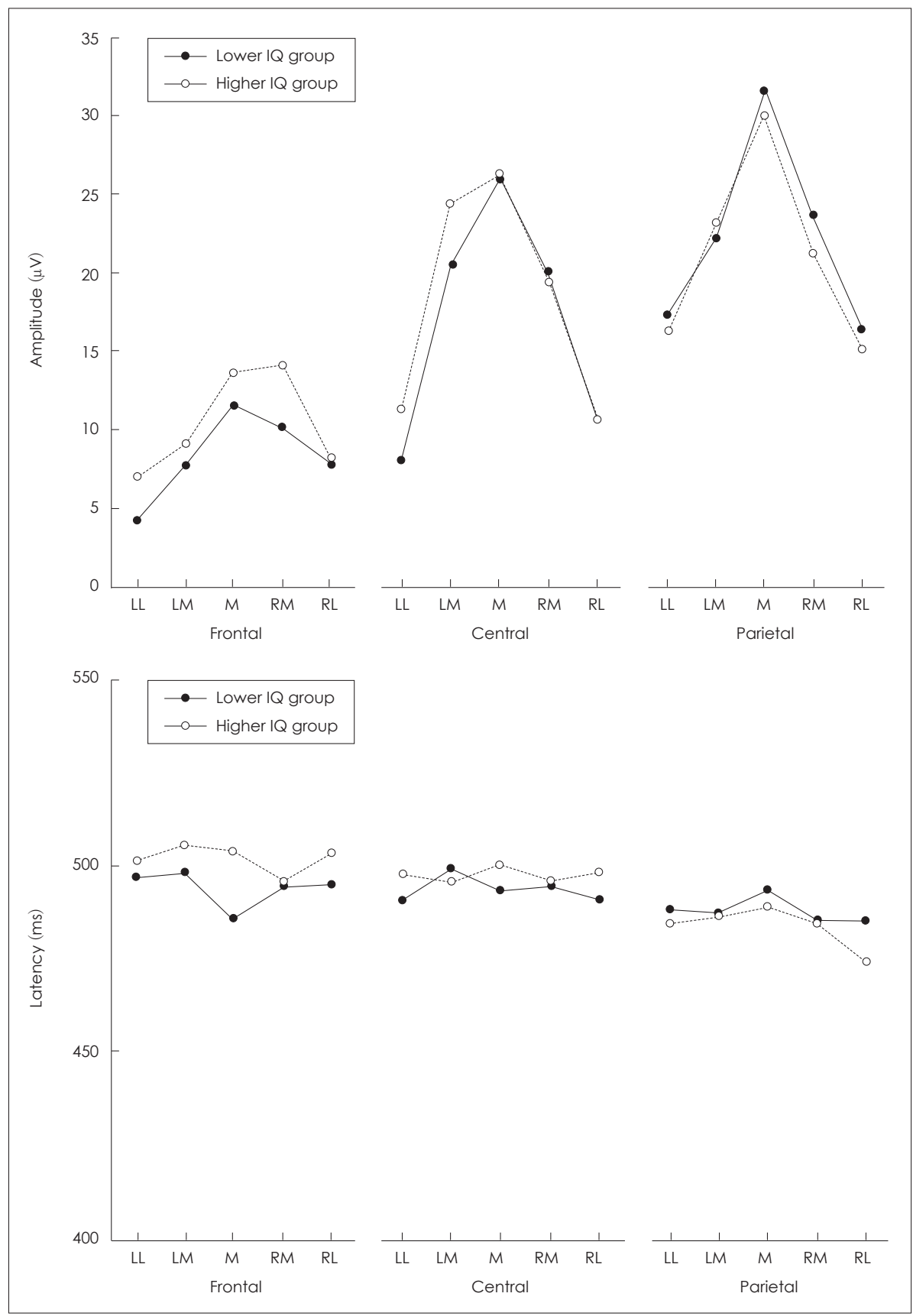

Fig. 2. Mean P300 amplitude (left panel) and latency (right panel) from target for visual stimuli condition from the frontal, fronto-central, central, centro-parietal, and parietal arrays as a function of the coronal electrode site (LL : left lateral, LM : left medial, $M$ : medial, $\mathrm{RM}$ : right medial, $\mathrm{RL}$ : right lateral) in ADHD children with lower and higher IQ

the independent effects of ADHD and intelligence on P3, and it is also difficult to generalize our result to all ADHD children with varying intelligence. Fourth, out of twenty participants, only two were females, making it difficult to generalize our result to both genders. In addition, since both female participants were included in the lower IQ group, it could have further resulted in various biases. Although analyses revealed that gender difference between the two groups were not statistically significant $(\mathrm{p}=.47)$, it is still possible that the parietal function difference between the two groups observed in this study might have been due to gender difference rather than

IQ difference. Finally, although subjects met DSM-IV-TR diagnostic criteria of ADHD-combined type, all having more than six inattention and hyperactivity-impulsivity symptoms, the subjects' detailed symptom severity was not mentioned. Thus, the symptom severity between the two IQ groups might have been different, and that difference might have affected the results.

Despite numerous limitations, the study has several strengths. According to our knowledge, this is the first study investigating P3 difference between ADHD children with lower IQs and those with higher IQs. Furthermore, the subjects exam- 
Table 4. Correlations between IQ and P300 from electrode sites in ADHD children

\begin{tabular}{|c|c|c|c|c|c|c|c|c|c|c|c|c|}
\hline & \multicolumn{6}{|c|}{ Auditory } & \multicolumn{6}{|c|}{ Visual } \\
\hline & \multicolumn{3}{|c|}{ Amplitude } & \multicolumn{3}{|c|}{ Latency } & \multicolumn{3}{|c|}{ Amplitude } & \multicolumn{3}{|c|}{ Latency } \\
\hline & $\mathrm{VIQ}$ & $P I Q$ & FISQ & $\mathrm{VIQ}$ & $P I Q$ & FSIQ & $\mathrm{VIQ}$ & $P I Q$ & $F S I Q$ & $\mathrm{VIQ}$ & $P I Q$ & FSIQ \\
\hline \multirow[t]{2}{*}{ F7 } & -.11 & .27 & .12 & .10 & -.26 & -.12 & .11 & .44 & .36 & -.04 & -.19 & -.14 \\
\hline & $p=.69$ & $p=.24$ & $p=.60$ & $p=.69$ & $p=.27$ & $\mathrm{p}=.61$ & $\mathrm{p}=.64$ & $p=.06$ & $\mathrm{p}=.12$ & $p=.88$ & $\mathrm{p}=.42$ & $\mathrm{p}=.54$ \\
\hline \multirow[t]{2}{*}{ F3 } & .24 & .23 & .01 & .18 & .29 & .09 & .06 & .37 & .28 & .08 & .12 & .12 \\
\hline & $p=.30$ & $p=.33$ & $p=.97$ & $p=.45$ & $\mathrm{p}=.21$ & $\mathrm{p}=.69$ & $\mathrm{p}=.83$ & $p=.11$ & $\mathrm{p}=.23$ & $p=.75$ & $p=.60$ & $p=.62$ \\
\hline \multirow[t]{2}{*}{$\mathrm{Fz}$} & -.44 & -.04 & -.28 & .12 & -.31 & -.14 & .00 & -.11 & -.06 & -.01 & -.06 & -.04 \\
\hline & $p=.05$ & $\mathrm{p}=.88$ & $p=.24$ & $p=.61$ & $p=.18$ & $\mathrm{p}=.55$ & $\mathrm{p}=.99$ & $p=.64$ & $\mathrm{p}=.79$ & $p=.97$ & $\mathrm{p}=.82$ & $\mathrm{p}=.88$ \\
\hline \multirow[t]{2}{*}{ F4 } & -.13 & .06 & -.04 & .07 & -.32 & -.18 & .20 & -.02 & .098 & -.14 & -.19 & -.20 \\
\hline & $\mathrm{p}=.60$ & $\mathrm{p}=.82$ & $\mathrm{p}=.85$ & $p=.76$ & $p=.16$ & $\mathrm{p}=.45$ & $\mathrm{p}=.40$ & $\mathrm{p}=.92$ & $p=.68$ & $\mathrm{p}=.55$ & $p=.43$ & $p=.39$ \\
\hline \multirow[t]{2}{*}{ F8 } & -.28 & -.16 & -.27 & .22 & -.34 & -.10 & -.01 & -.28 & -.20 & -.30 & -.16 & -.27 \\
\hline & $\mathrm{p}=.23$ & $\mathrm{p}=.50$ & $\mathrm{p}=.25$ & $\mathrm{p}=.35$ & $p=.15$ & $\mathrm{p}=.68$ & $\mathrm{p}=.96$ & $\mathrm{p}=.24$ & $\mathrm{p}=.41$ & $p=.20$ & $\mathrm{p}=.51$ & $\mathrm{p}=.24$ \\
\hline \multirow[t]{2}{*}{ T7 } & -.21 & -.10 & -.19 & .07 & -.35 & -.20 & .02 & .01 & .02 & -.03 & -.10 & -.09 \\
\hline & $p=.37$ & $p=.08$ & $\mathrm{p}=.42$ & $p=.77$ & $p=.13$ & $\mathrm{p}=.41$ & $\mathrm{p}=.94$ & $\mathrm{p}=.97$ & $\mathrm{p}=.95$ & $\mathrm{p}=.89$ & $\mathrm{p}=.68$ & $\mathrm{p}=.72$ \\
\hline \multirow[t]{2}{*}{$\mathrm{C} 3$} & -.13 & .14 & .00 & .17 & -.25 & -.07 & -.04 & .31 & .18 & -.16 & -.24 & -.25 \\
\hline & $\mathrm{p}=.58$ & $\mathrm{p}=.55$ & $\mathrm{p}=.98$ & $\mathrm{p}=.48$ & $\mathrm{p}=.29$ & $p=.76$ & $\mathrm{p}=.88$ & $\mathrm{p}=.18$ & $\mathrm{p}=.45$ & $\mathrm{p}=.50$ & $\mathrm{p}=.30$ & $\mathrm{p}=.29$ \\
\hline \multirow[t]{2}{*}{$\mathrm{Cz}$} & -.08 & .12 & .03 & .10 & -.32 & -.16 & -.06 & .09 & .03 & -.07 & -.19 & -.16 \\
\hline & $\mathrm{p}=.75$ & $p=.60$ & $\mathrm{p}=.90$ & $\mathrm{p}=.69$ & $\mathrm{p}=.18$ & $\mathrm{p}=.51$ & $\mathrm{p}=.80$ & $\mathrm{p}=.70$ & $\mathrm{p}=.91$ & $p=.78$ & $\mathrm{p}=.42$ & $\mathrm{p}=.50$ \\
\hline \multirow[t]{2}{*}{$\mathrm{C} 4$} & -.22 & .08 & -.09 & .05 & -.38 & -.23 & .17 & .16 & -.00 & -.15 & -.24 & -.24 \\
\hline & $\mathrm{p}=.35$ & $\mathrm{p}=.75$ & $\mathrm{p}=.71$ & $\mathrm{p}=.85$ & $p=.10$ & $\mathrm{p}=.33$ & $\mathrm{p}=.46$ & $\mathrm{p}=.51$ & $\mathrm{p}=.99$ & $\mathrm{p}=.52$ & $\mathrm{p}=.31$ & $\mathrm{p}=.31$ \\
\hline \multirow[t]{2}{*}{ T8 } & -.14 & -.14 & -.18 & .15 & -.39 & -.17 & .11 & -.22 & -.22 & -.18 & -.22 & -.24 \\
\hline & $\mathrm{p}=.56$ & $\mathrm{p}=.57$ & $p=.46$ & $\mathrm{p}=.53$ & $\mathrm{p}=.09$ & $\mathrm{p}=.47$ & $p=.65$ & $\mathrm{p}=.35$ & $p=.36$ & $p=.45$ & $\mathrm{p}=.35$ & $\mathrm{p}=.30$ \\
\hline \multirow[t]{2}{*}{ P7 } & -.39 & .16 & -.12 & .39 & -.03 & -.20 & .18 & .15 & -.01 & -.04 & -.19 & -.16 \\
\hline & $\mathrm{p}=.09$ & $\mathrm{p}=.49$ & $\mathrm{p}=.61$ & $p=.09$ & $\mathrm{p}=.91$ & $\mathrm{p}=.39$ & $\mathrm{p}=.45$ & $\mathrm{p}=.52$ & $\mathrm{p}=.98$ & $\mathrm{p}=.86$ & $\mathrm{p}=.42$ & $\mathrm{p}=.51$ \\
\hline \multirow[t]{2}{*}{ P3 } & -.18 & .26 & .05 & .21 & -.16 & .01 & -.07 & .57 & .33 & -.06 & -.20 & -.17 \\
\hline & $\mathrm{p}=.45$ & $\mathrm{p}=.27$ & $\mathrm{p}=.82$ & $p=.38$ & $\mathrm{p}=.51$ & $\mathrm{p}=.97$ & $p=.77$ & $\mathrm{p}=.01 *$ & $\mathrm{p}=.15$ & $\mathrm{p}=.81$ & $\mathrm{p}=.39$ & $\mathrm{p}=.48$ \\
\hline \multirow[t]{2}{*}{$\mathrm{Pz}$} & -.19 & .37 & .13 & .15 & -.27 & -.10 & -.14 & .37 & .16 & -.12 & -.23 & -.22 \\
\hline & $p=.42$ & $p=.11$ & $\mathrm{p}=.59$ & $\mathrm{p}=.53$ & $\mathrm{p}=.24$ & $\mathrm{p}=.68$ & $\mathrm{p}=.56$ & $p=.11$ & $\mathrm{p}=.49$ & $p=.61$ & $\mathrm{p}=.33$ & $p=.36$ \\
\hline \multirow[t]{2}{*}{ P4 } & -.34 & .20 & -.07 & .20 & -.24 & -.05 & -.15 & .17 & .03 & -.09 & -.30 & -.24 \\
\hline & $\mathrm{p}=.14$ & $p=.39$ & $p=.78$ & $\mathrm{p}=.41$ & $\mathrm{p}=.31$ & $\mathrm{p}=.84$ & $\mathrm{p}=.54$ & $\mathrm{p}=.48$ & $\mathrm{p}=.91$ & $p=.71$ & $\mathrm{p}=.21$ & $p=.30$ \\
\hline \multirow[t]{2}{*}{ P8 } & -.50 & .15 & -.19 & .13 & -.30 & -.13 & -.16 & .02 & -.08 & -.22 & -.37 & -.37 \\
\hline & $\mathrm{p}=.03^{*}$ & $\mathrm{p}=.53$ & $\mathrm{p}=.43$ & $\mathrm{p}=.60$ & $\mathrm{p}=.19$ & $\mathrm{p}=.59$ & $\mathrm{p}=.51$ & $p=.97$ & $\mathrm{p}=.73$ & $p=.34$ & $\mathrm{p}=.11$ & $p=.11$ \\
\hline
\end{tabular}

$*: p<0.05 . V I Q:$ Verbal IQ, PIQ : Performance IQ, FSIQ : Full Scale IQ

ined were carefully defined and selected. Thus, we believe that the result of this paper may help guide future research on understanding pathological differences between ADHD children with lower IQs and those with higher IQ. By understanding these differences, more efficient and specific treatment modalities could be developed for ADHD children according to their specific intellectual abilities. Lastly, we suggest that more controlled trials with larger samples are needed to address the issue.

\section{References}

1) American Psychiatric Association. Diagnostic and statistical manual of mental disorders. 4th ed. Washington DC: American Psychiatric Press; 1994.

2) Steinhausen HC, Drechsler R, Foldenyi M, Imhof K, Brandeis D. Clinical course of attention-deficit/hyperactivity disorder from childhood toward early adolescence. J Am Acad Child Adolesc Psychiatry 2003;42:1085-1092.

3) Biederman J, Faraone SV, Keenan K, Benjamin J, Krifcher B, Moore C, et al. Further evidence for family-genetic risk factors in attention deficit hyperactivity disorder. Patterns of comorbidity in probands and relatives psychiatrically and pediatrically referred samples. Arch Gen Psychiatry 1992;49:728-738.

4) Biederman J, Newcorn J, Sprich S. Comorbidity of attention deficit hyperactivity disorder with conduct, depressive, anxiety, and other disorders. Am J Psychiatry 1991;148:564-577.

5) Wilens TE, Biederman J, Mick E. Does ADHD affect the course of substance abuse? Findings from a sample of adults with and without ADHD. Am J Addict 1998;7:156-163.

6) Spencer TJ, Biederman J, Mick E. Attention-deficit/hyperactivity disorder: diagnosis, lifespan, comorbidities, and neurobiology. Ambul Pediatr 2007;7:73-81.

7) Katusic MZ, Voigt RG, Colligan RC, Weaver AL, Homan KJ, Barbaresi WJ. Attention-deficit hyperactivity disorder in children with high intelligence quotient: results from a population-based study. J Dev Behav Pediatr 2011;32:103-109.

8) Voigt RG, Barbaresi WJ, Colligan RC, Weaver AL, Katusic SK. Developmental dissociation, deviance, and delay: Occurrence of attention-deficit-hyperactivity disorder in individuals with and without borderline-to-mild intellectual disability. Dev Med Child Neurol 2006;48:831-835.

9) Owens EB, Hinshaw SP, Kraemer HC, Arnold LE, Abikoff HB, Cantwell DP, et al. Which treatment for whom for ADHD? Moderators of treatment response in the MTA. J Consult Clin Psychol 2003;71:540-552.

10) Aman MG, Armstrong S, Buican B, Sillick T. Four-year follow-up of children with low intelligence and ADHD: a replication. Res Dev Disabil 2002;23:119-134. 
11) Aman MG, Kern RA, McGhee DE, Arnold LE. Fenfluramine and methylphenidate in children with mental retardation and ADHD: clinical and side effects. J Am Acad Child Adolesc Psychiatry 1993; 32:851-859.

12) Banaschewski T, Brandeis D. Annotation: what electrical brain activity tells us about brain function that other techniques cannot tell us - a child psychiatric perspective. J Child Psychol Psychiatry 2007;48:415-435.

13) Donchin E, Coles MGH. Is the P300 component a manifestation of context updating. Behav Brain Science 1988:11:357-374.

14) Polich J. Updating P300: an integrative theory of P3a and P3b. Clin Neurophysiol 2007;118:2128-2148.

15) Michie PT. Cognitive deficits in psychopathology: insight from event-related potentials. In: Johnson R Jr, Baron JC, editors. Handbook of Neuropsychology. Amsterdam: Elsevier;1995. p.299-330.

16) Barry RJ, Johnstone SJ, Clarke AR. A review of electrophysiology in attention-deficit/hyperactivity disorder: II. Event-related potentials. Clin Neurophysiol 2003;114:184-198.

17) Jausovec N. Differences in cognitive processes between gifted, intelligent, creative, and average individuals while solving complex problems: an EEG study. Intelligence 2000;28:213-237.

18) Halligan PW, Fink GR, Marshall JC, Vallar G. Spatial cognition: evidence from visual neglect. Trends Cogn Sci 2003;7:125-133.

19) Ross ED. Left medial parietal lobe and receptive language functions: mixed transcortical aphasia after left anterior cerebral artery infarction. Neurology 1980;30:144-151.

20) Cipolotti L, de Lacy Costello A. Selective impairment for simple division. Cortex 1995;31:433-449.

21) Cohen L, Dehaene S, Chochon F, Lehéricy S, Naccache L. Language and calculation within the parietal lobe: a combined cognitive, anatomical and fMRI study. Neuropsychologia 2000;38:1426-
1440.

22) Bush G, Valera EM, Seidman LJ. Functional neuroimaging of attention-deficit/hyperactivity disorder: a review and suggested future directions. Biol Psychiatry 2005;57:1273-1284.

23) Tamm L, Menon V, Reiss AL. Parietal attentional system aberrations during target detection in adolescents with attention deficit hyperactivity disorder: event-related fMRI evidence. Am J Psychiatry 2006;163:1033-1043.

24) Vance A, Silk TJ, Casey M, Rinehart NJ, Bradshaw JL, Bellgrove MA, et al. Right parietal dysfunction in children with attention deficit hyperactivity disorder, combined type: a functional MRI study. Mol Psychiatry 2007;12:826-832.

25) Booth JR, Burman DD, Meyer JR, Lei Z, Trommer BL, Davenport ND, et al. Larger deficits in brain networks for response inhibition than for visual selective attention in attention deficit hyperactivity disorder (ADHD). J Child Psychol Psychiatry 2005;46:94-111.

26) van Leeuwen TH, Steinhausen HC, Overtoom CC, Pascual-Marqui RD, van't Klooster B, Rothenberger A, et al. The continuous performance test revisited with neuroelectric mapping: impaired orienting in children with attention deficits. Behav Brain Res 1998;94: 97-110.

27) Brandeis D, van Leeuwen TH, Rubia K, Vitacco D, Steger J, Pascual-Marqui RD, et al. Neuroelectric mapping reveals precursor of stop failures in children with attention deficits. Behav Brain Res 1998;94:111-125.

28) Ikeda K, Hashimoto S, Hayashi A, Kanno A. ERP evaluation of auditory sensory memory systems in adults with intellectual disability. Int J Neurosci 2009;119:778-791.

29) Jausovec N, Jausovec K. Differences in EEG current density related to intelligence. Brain Res Cogn Brain Res 2001;12:55-60. 